\title{
The Appropriateness of Long-term Opioids to Treat Chronic Back Pain
}

Thomas Watanabe

Moss Rehab

Michael Salino

Moss Rehab

Adam Schreiber

Department of Rehabilitation Medicine, Thomas Jefferson University Hospital

Follow this and additional works at: https://jdc.jefferson.edu/rmfp

Part of the Neurology Commons, and the Physical Therapy Commons

Let us know how access to this document benefits you

\section{Recommended Citation}

Watanabe, Thomas; Salino, Michael; and Schreiber, Adam, "The Appropriateness of Long-term Opioids to Treat Chronic Back Pain" (2012). Department of Rehabilitation Medicine Faculty Papers. Paper 17.

https://jdc.jefferson.edu/rmfp/17

This Article is brought to you for free and open access by the Jefferson Digital Commons. The Jefferson Digital Commons is a service of Thomas Jefferson University's Center for Teaching and Learning (CTL). The Commons is a showcase for Jefferson books and journals, peer-reviewed scholarly publications, unique historical collections from the University archives, and teaching tools. The Jefferson Digital Commons allows researchers and interested readers anywhere in the world to learn about and keep up to date with Jefferson scholarship. This article has been accepted for inclusion in Department of Rehabilitation Medicine Faculty Papers by an authorized administrator of the Jefferson Digital Commons. For more information, please contact: JeffersonDigitalCommons@jefferson.edu. 


\title{
Point/Counterpoint
}

\author{
Guest Discussants: \\ Michael Saulino, MD, PhD \\ Moss Rehab, Elkins Park, PA \\ Disclosure: nothing to disclose
}

\section{Adam Schreiber, DO}

Department of Rehabilitation Medicine,

Thomas Jefferson University,

Philadelphia, PA

Disclosure: nothing to disclose

\section{Feature Editor:}

Thomas Watanabe, MD

MossRehab, Elkins Park, PA. Address

correspondence to: T.W.; e-mail:

watanabt@einstein.edu

Disclosure: nothing to disclose

\section{CASE SCENARIO}

A 55-year-old man presents to a pain clinic upon referral from his primary care physician. His symptom is axial low back pain. His pain started approximately 1 year earlier without a specific inciting event. He denies radiation of pain into the lower extremities. There is no bowel or bladder involvement. There is no directional preference. He reports pain "all the time," with minimal specific exacerbating or relieving factors. There is no medical-legal involvement. His medical history is significant for hypertension, hypercholesterolemia, obesity, and sleep apnea. He is a divorced father of 2 adult children. He is self-employed local truck driver, and his job also involves some loading and unloading of boxes, although he describes the weight of the boxes as "light." He notes a decreased capacity to complete job-related activities but states that the pain medication (sustained-release oxycodone, $80 \mathrm{mg}$ twice a day) allows him to work with minimal discomfort.

The physical examination is notable for diffusely limited lumbar range of motion without a directional preference for pain reduction. Strength examination demonstrates pain-limited weakness in the proximal bilateral lower extremities. There is no abnormality of sensation or deep tendon reflexes. He has diffuse tenderness over the lumbar paraspinal, quadratus lumborum laborum, gluteal, and piriformis muscles. There is no tenderness over the sacroiliac joints. Gaenslen, flexion abduction external rotation (FABER), slump, and straight-leg raising testing is negative. He is $5 \mathrm{ft}, 11 \mathrm{in}$. tall and weighs $230 \mathrm{lb}$.

His primary care physician ordered magnetic resonance imaging of the lumbar spine, which demonstrated mild degeneration of multiple intervertebral disks without nerve root compression. He has tried physical therapy, nonsteroidal anti-inflammatory drugs, and cyclobenzaprine, without sustained relief. He has had bilateral lumbar selective nerve root injections at L5 and S1 as well as bilateral facet injections at L4-5 and L5-S1 without improvement. The primary care physician notes that the patient appears to have done well on the sustained-release oxycodone, but the physician feels uncomfortable with continuing to manage the pain with high doses of opioid pain medication. The physician believes that the patient is taking the medication appropriately, but he concedes that he does not have a formal program in place to help ensure that there is no medication diversion. He also is concerned about the appropriateness of having his patient taking high doses of opioid medications because his primary job task is driving.

What is your treatment recommendation, and how do you specifically plan to 
address the issues related to long-term opioid use?

\section{Michael Saulino, MD, PhD, Responds}

The described patient fits with the criteria for chronic pain (1). He has undergone a thorough diagnostic investigation. At least at present, further testing would not appear warranted. While not completely exhaustive, there have been reasonable therapeutic maneuvers. Further inquiry into the patient's history should explore the nature of the physical therapy sessions. It is conceivable that the rehabilitative strategies may have been inappropriate. Perhaps the patient's program focused on application of modalities rather than therapeutic exercise, stretching, functional retraining and ergonomics. If these latter strategies have not been employed, a referral to an alternative therapist would be appropriate. The history does not comment upon other non-pharmacologic approaches to chronic low back pain. Several options are available including acupuncture, massage therapy, yoga, cognitive-behavioral therapy and spinal manipulation. The evidence basis demonstrating the long-term effectiveness for these different therapies varies from fair to good (2). With regards to medication therapy, the patient's PCP has explored a rational approach to date. Conceivably, alternative medications could be attempted. Notably absent is an exposure to antidepressants, which represent another reasonable strategy (3). Other potential agents include acetaminophen, NSAIDS, skeletal muscle relaxants and anti-epileptic medications. These agents to not precisely fit this patient's presentation since the first three medication classes are typically used in acute pain syndromes while the latter class is classically associated with chronic neuropathic pain. Each of these medication categories is associated with unique trade-offs involving benefits, risks, and costs (2). Conceivably, a trial of botulinum toxin injections if coupled with a functional retraining strategy could be attempted but this approach similarly lacks substantive evidence basis from randomized controlled trials (4). Additionally, given the duration of the patient's pain syndrome, a referral for neuromodulation (spinal cord stimulation or intrathecal therapy) would not be unwarranted (5). However, given the patient's positive response to oral opioids, it is entirely appropriate to maintain the patient on this type of medication. The remainder of this discourse will present the rationale for this opinion.

All therapeutic inventions in medicine require a risk benefit analysis by the treating physician. This decision making is so fundamental to medical practice that is one of the six core competencies defined by both the ACGME and ABMS is systems-based practice, where risk-benefit analysis is specifically delineated as basic skill for trainees and board-certified physicians alike (6). Perhaps, no other decision is medicine causes more anxiety that prescribing opiates for patients with chronic, non-cancer pain (CNCP). Concerns over diversion, misuse, dependence, addiction, monitoring and cost can make the analysis of utilizing chronic opiate therapy (COT) troublesome for even experienced practitioners (7).

The American Pain Society (APS) and the American Academy of Pain Medicine (AAPM) have jointly put forth a set of guidelines for COT in CNCP (8). The primary 
means of support for COT in this patient will be to determine how well this scenario fits within these guidelines. The first set of recommendations describes patient selection and risk stratification. Three elements within this set were put forth: (1) before initiating COT, clinician should conduct a history, physical examination (PE) and appropriate testing, including an assessment of risk of substance abuse, misuse or addiction; (2) clinicians may consider COT as an option if CNCP is moderate or severe, pain is having an adverse impact on function or quality of life, and potential therapeutic benefits outweigh or are likely to outweigh potential harms; (3) a benefit-to-harm evaluation including a history, PE and appropriate diagnostic testing should be performed and before and on an ongoing basis during COT. In the described patient, the history, PE and diagnostic testing have been undertaken in an exquisite and detailed manner. The history does not put forth any episodes of abuse, misuse or addiction. These components should be queried. In their absence, the first element is fully satisfied. Even if abuse, misuse, diversion or addiction were to be elicited in this patient, COT would not be contraindicated. Weaver and Schnoll (2002) delineate that the undertreatment of pain in patients with addiction histories is more likely than adequate treatment to lead to drugseeking behavior in recovering addicts. Such individuals may require a greater level of scrutiny and monitoring with potential consultation with addiction management professionals. The first component of these guidelines would appear accomplished. With regards to the second element, it is not clear from the history if a pain intensity or rating was formally assessed. This assessment should be undertaken and documented (9). Clearly, the patient's pain complex is functionally limiting. Thus, regardless of a pain rating, the second element would appear satisfied. Lastly, a benefit to harm analysis should be explored. The history does not put forth any apparent adverse effects from the patient's current exposure to COT. As with all medications, potential untoward effects can occur. For COT, this would include sedation, dizziness, nausea, vomiting, constipation, physical dependence, tolerance, and respiratory depression (10). The patient should be specifically queried as to presence or severity of these symptoms. The prescribing physician may need to alter this treatment approach based on these adverse effects. However, given their absence in the proposed patient, the purported benefit would appear to outweigh the risk of harm.

There are several survey instruments available to clinicians that can assist in the decision making relative to COT. One tool is Screener and Opioid Assessment for Patients with Pain-Revised (SOAPP-R). This survey is self-reported questionnaire designed to predict aberrant medication-related behaviors among chronic pain patients considered for COT. The given history does not provide sufficient inquiry into these questions, so this assessment cannot be formally utilized at this point. Another instrument that can be utilized in this patient is the Opioid Risk Tool (ORT). This is another self-administered questionnaire that utilizes personal and family history in an effort to predict aberrant behavior. Again, the described history does not provide sufficient detail to apply this instrument. Yet another screening tool that can be utilized the DIRE (Diagnosis, Intractability, Risk and Efficacy) score. There is sufficient history to apply this tool to the described patient. This analysis is reported in Table 1. Even with the most conservative 
estimate, the patient would be considered a reasonable candidate for COT. The validity, reliability, sensitivity and predicative value of these tools is considered fair to good (11).

One particular concern for this clinical scenario is driving while utilizing COT. Each state regulates the parameters for routine driving licensure but, in general, physicians are required to restrict driving in any individual where potential impairment is present. While there is some data to suggest that the skills needed for safe driving are impaired with acute opiate use (12-3), evidence to support the assertion that COT uniformly results in significant driving impairment is lacking (14). From an epidemiologic perspective, there is little substantiation that COT in isolation results in increased rate of motor vehicle accidents (15). With regards to a commercial drivers license (CDL), Federal law (49 CFR 391.41) mandates that an individual who is applying for a CDL "has no established medical history or clinical diagnosis of rheumatic, arthritic, orthopedic, muscular, neuromuscular, or vascular disease which interferes with his ability to control and operate a commercial motor vehicle safely" and "does not use a Schedule 1 controlled substance, an amphetamine, a narcotic, or any other habit-forming drug." However, there is an exception in latter regulation that "A driver may use such a substance or drug, if the substance or drug is prescribed by a licensed medical practitioner who: (A) is familiar with the driver's medical history and assigned duties; and (B) has advised the driver that the prescribed substance or drug will not adversely affect the driver's ability to safely operate a commercial motor vehicle." While the clinical scenario does not specify if the individual has a regular or commercial driver license, there is minimal evidence in the described patient that sufficient impairment exists to restrict driving at present.

In summary, COT is a reasonable therapeutic maneuver for this patient. A well-trained physiatrist should be capable of maintaining the patient on this regimen, which would include routine monitoring for sustained analgesia, adverse effects, aberrant behaviors as well as correlative functional status. COT should not be the totality of the patient's regimen but it can be a safe, effective, and appropriate element of comprehensive pain management.

Table 1. D.I.R.E. Score (Patient Selection for Chronic Opioid Analgesia) with scoring for proposed patient).

\begin{tabular}{|l|l|l|l|}
\hline Factor & Explanation & $\begin{array}{l}\text { Conservative } \\
\text { estimate of } \\
\text { proposed } \\
\text { patient }\end{array}$ & $\begin{array}{l}\text { Liberal } \\
\text { estimate of } \\
\text { proposed } \\
\text { patient }\end{array}$ \\
\hline Diagnosis & $\begin{array}{l}1=\text { Benign chronic condition with } \\
\text { minimal objective findings or no definite } \\
\text { medical diagnosis. } \\
\text { 2= Slowly progressive condition } \\
\text { concordant with moderate pain, or fixed }\end{array}$ & 2 & 3 \\
\hline
\end{tabular}




\begin{tabular}{|c|c|c|c|}
\hline & $\begin{array}{l}\text { condition with moderate objective } \\
\text { findings. } \\
3=\text { Advanced condition concordant with } \\
\text { severe pain with objective findings. }\end{array}$ & & \\
\hline Intractability & $\begin{array}{l}1=\text { Few therapies have been tried and the } \\
\text { patient takes a passive role in his/her pain } \\
\text { management process. } \\
2=\text { Most customary treatments have been } \\
\text { tried but the patient is not fully engaged in } \\
\text { the pain management process, or barriers } \\
\text { prevent } \\
3=\text { Patient fully engaged in a spectrum of } \\
\text { appropriate treatments but with inadequate } \\
\text { response. }\end{array}$ & 2 & 3 \\
\hline \multicolumn{4}{|l|}{ Risk } \\
\hline Psychologic & $\begin{array}{l}1=\text { Serious personality dysfunction or } \\
\text { mental illness interfering with care. } \\
2=\text { Personality or mental health interferes } \\
\text { moderately. } \\
3=\text { Good communication with clinic. No } \\
\text { significant personality dysfunction or } \\
\text { mental illness. }\end{array}$ & 2 & 3 \\
\hline Chemical Health & $\begin{array}{l}1=\text { Active or very recent use of illicit } \\
\text { drugs, excessive alcohol, or prescription } \\
\text { drug abuse. } \\
2=\text { Chemical coper or history of chemical } \\
\text { depenedence in remission. } \\
3=\text { No CD history. Not drug-focused or } \\
\text { chemically reliant. }\end{array}$ & 3 & 3 \\
\hline Reliability & $\begin{array}{l}1=\text { History of numerous problems: } \\
\text { medication misuse, missed appointments, } \\
\text { rarely follows through. } \\
2=\text { Occasional difficulties with } \\
\text { compliance, but generally reliable. } \\
3=\text { Highly reliable patient with meds, } \\
\text { appointments \& treatment. }\end{array}$ & 3 & 3 \\
\hline Social support & $\begin{array}{l}1=\text { Life in chaos. Little family support } \\
\text { and few close relationships. Loss of most } \\
\text { normal life roles. } \\
2=\text { Reduction in some relationships and } \\
\text { life roles. } \\
3=\text { Supportive family/close relationships. }\end{array}$ & 2 & 3 \\
\hline
\end{tabular}




\begin{tabular}{|c|c|c|c|}
\hline & $\begin{array}{l}\text { Involved in work or school and no social } \\
\text { isolation. }\end{array}$ & & \\
\hline Efficacy & $\begin{array}{l}1=\text { Poor function or minimal pain relief } \\
\text { despite moderate to high doses. } \\
2=\text { Moderate benefit with function } \\
\text { improved in a number of ways } \\
3=\text { Good improvement in pain and } \\
\text { function and quality of life with stable } \\
\text { doses over time. }\end{array}$ & 2 & 3 \\
\hline Total & & 16 & 21 \\
\hline
\end{tabular}

Score 7-13: Not a suitable candidate for long-term opioid analgesia

Score 14-21: May be a candidate for long-term opioid analgesia

\section{References}

1. Holding MY, Saulino MF, Overton EA, Kornbluth ID, Freedman MK. Interventions in chronic pain management. 1. update on important definitions in pain management. Arch Phys Med Rehabil. 2008 Mar;89(3 Suppl 1):S38-40.

2. Chou R, Qaseem A, Snow V, Casey D, Cross JT,Jr, Shekelle P, et al. Diagnosis and treatment of low back pain: A joint clinical practice guideline from the american college of physicians and the american pain society. Ann Intern Med. 2007 Oct 2;147(7):478-91.

3. Dharmshaktu P, Tayal V, Kalra BS. Efficacy of antidepressants as analgesics: A review. J Clin Pharmacol. 2012 Jan;52(1):6-17.

4. Waseem Z, Boulias C, Gordon A, Ismail F, Sheean G, Furlan AD. Botulinum toxin injections for low-back pain and sciatica. Cochrane Database Syst Rev. 2011 Jan 19;(1)(1):CD008257.

5. Krames E, Poree L, Deer T, Levy R. Implementing the SAFE principles for the development of pain medicine therapeutic algorithms that include neuromodulation techniques. Neuromodulation. 2009 Apr;12(2):104-13.

6. Heffron MG, Simspon D, Kochar MS. Competency-based physician education, recertification, and licensure. WMJ. 2007 Jul;106(4):215-8.

7. Hallinan R, Osborn M, Cohen M, Dobbin M, Wodak A. Increasing the benefits and reducing the harms of prescription opioid analgesics. Drug Alcohol Rev. 2011 May;30(3):315-23. 
8. Chou R, Fanciullo GJ, Fine PG, Adler JA, Ballantyne JC, Davies P, et al. Clinical guidelines for the use of chronic opioid therapy in chronic noncancer pain. J Pain. 2009 Feb;10(2):113-30.

9. Von Korff M, Ormel J, Keefe FJ, Dworkin SF. Grading the severity of chronic pain. Pain. 1992 Aug;50(2):133-49.

10. Benyamin R, Trescot AM, Datta S, Buenaventura R, Adlaka R, Sehgal N, et al. Opioid complications and side effects. Pain Physician. 2008 Mar;11(2 Suppl):S105-20.

11. Jones T, Moore T, Levy JL, Daffron S, Browder JH, Allen L, et al. A comparison of various risk screening methods in predicting discharge from opioid treatment. Clin J Pain. 2012 Feb;28(2):93-100.

12. Linnoila M, Hakkinen S. Effects of diazepam and codeine, alone and in combination with alcohol, on simulated driving. Clin Pharmacol Ther. 1974 Apr;15(4):368-73.

13. Verster JC, Veldhuijzen DS, Volkerts ER. Effects of an opioid (oxycodone/paracetamol) and an NSAID (bromfenac) on driving ability, memory functioning, psychomotor performance, pupil size, and mood. Clin J Pain. 2006 Jun;22(5):499-504.

14. Menefee LA, Frank ED, Crerand C, Jalali S, Park J, Sanschagrin K, et al. The effects of transdermal fentanyl on driving, cognitive performance, and balance in patients with chronic nonmalignant pain conditions. Pain Med. 2004 Mar;5(1):42-9.

15. Dassanayake T, Michie P, Carter G, Jones A. Effects of benzodiazepines, antidepressants and opioids on driving: A systematic review and meta-analysis of epidemiological and experimental evidence. Drug Saf. 2011 Feb 1;34(2):125-56. 
Adam Schreiber, DO, Responds

\section{The Cyclical Opioid Epidemic?}

\section{Brief History of Opioids in the US}

Morphine was developed as a pain killer around 1810 and greatly diminished severe pain associated with medical operations or traumatic injuries. It also produced a numb euphoric state. In the 1850's, morphine was available in the United States (US) and became a treatment by physicians, however the side effect of addiction became apparent with many Civil War soldiers; thereafter the US was plagued with a morphine epidemic. Reputable drug companies began manufacturing over-the-counter drug kits containing glass barreled hypodermic needle and vials of morphine or heroin packaged neatly in attractive engraved tin cases. ${ }^{1}$ These products were marketed as the cure for all types of physical and mental ailments ranging from alcohol withdrawal to cancer, depression, sluggishness, coughs, colds, tuberculosis and old age.

In the 1980s, opioid use was largely limited to cancer and acute pain; it was considered inappropriate for chronic pain management owing to concerns about adverse effects, tolerance, dependence, and addiction. In 1986, a study concluded that chronic opioid therapy could be safe for patients with noncancer pain. ${ }^{2}$ During the 1990 s, some clinicians encouraged the use of opioids due to concern for undertreatment of chronic pain with the thought that opioid therapy had no ceiling and that it was appropriate to escalate "to effect," regardless of the amounts prescribed. ${ }^{3}$

In 1995, one hundred and forty five years after morphine became a marketable product in the US, a long acting oxycodone (OxyContin) was "packaged neatly" with the marketing strategy by Purdue Pharma of having low abuse potential. OxyContin was rapidly utilized earning almost a billion dollars for Purdue Pharma in the first years of its release. Purdue raised awareness of pain management for patients which was largely overlooked as abuse started spreading and drug abusers discovered with manipulation of drug delivery that it could give a quick "high", but frequent overdosing followed.

With the paradigm shift in treatment of chronic pain, opioid prescribing in the US has increased dramatically (108\% from 1997-2004), and associated expense of $423 \%$ inflation adjusted increase in expenditure. ${ }^{4}$ Hydrocodone is now the most commonly prescribed medication with concomitant rise in opioid-related abuse, overdoses, and deaths. ${ }^{5}$ Chronic pain places enormous physical, emotional and financial pressure on society with prevalence rates ranging from $10 \%$ to $50 \%{ }^{6}$ It is estimated that $5 \%$ of people with LBP account for $75 \%$ of the costs associated with it. With opioid overdoses paralleling the number of prescriptions ${ }^{7}$, and population based studies indicating opioid use for non cancer pain still results in persistent high levels of pain and poor quality of life ${ }^{8}$ we must admit to a cyclical opioid epidemic. 


\section{Our Patient's Situation}

With a 55 year-old on long-acting oxycodone, $80 \mathrm{mg}$ BID, we anticipate him needing this for approximately 30-35 more years, and possibly requiring titration; a significant financial expense. The side effects of cognitive difficulties, apathy, depression, and fatigue may be major barriers to him living a healthy, and happy functional life. As he ages, these side effects will contribute to increasing risk of falls, which carries significant morbidities. With his opioid dependence, a commitment from the doctor to the patient and patient to the doctor is necessary. He will need to see his physician regularly to prevent withdrawal and therefore potential for emergency room visits (another expense and stressor to the medical system), or the illegal activity of turning to the streets for a supply. Another issue is diversion, are we providing him with income and the possibility of providing others with medication illegally?

\section{Era of evidence-based medicine}

In an era of evidence-based medicine, reviews of opioid use for chronic LBP compared with placebo or non-opioid analgesics suggest that these medications do not significantly reduce pain and that substance abuse disorders are common. There is a lack of quality studies on the safety and efficacy of long-term opioid therapy for LBP. ${ }^{9}$ Research shows increased risk of opioid overdoses in patients receiving higher prescribed doses of opioids for pain. ${ }^{10}$ There is no evidence for opioids for LBP improving functional disability or self-assessed health status. ${ }^{11}$

Evidence indicates that chronic LBP patients are best served by a comprehensive treatment approach ${ }^{12}$, which includes a biopsychosocial model, in contrast to isolated opioid treatment. The biopsychosocial model views chronic pain as a complex experience that affects and is influenced by an individual's physical, emotional, cognitive and social health. ${ }^{13}$ The intervention involves multidisciplinary and multimodal treatments emphasizing adaptive self-management with goals to improve long-term health, activity, and quality of life. These goals are attained by including patient education, medications, physical therapy and exercise, cognitive-behavioral therapy and social services. This approach is cost-effective and has evidence-based positive longterm results such as improving return to work, and reducing additional surgery and health-care use. ${ }^{13}$

However third-party payers are not reimbursing many of the cost-effective components of comprehensive pain care caused closure of these multidisciplinary pain programs and this led to the expansion of pain clinics that deliver pharmacologic treatments and/or spinal procedures, both of which have contributed significantly to the high health-care costs associated with LBP without strong evidence of efficacy. ${ }^{3}$ Third-party payers perceive opioid treatment as a quicker, less cumbersome way of efficiently treating these patients.

\section{How has our patient been treated and how should he be treated?}

Further examination of the etiologies for low back pain in this patient is warranted but beyond the scope of this discussion. At this point, we will assume that the treatment goal has changed from curative to recovery of health and function. We will review actual and 
possible treatments. Treatments can be broken into five categories: therapy, injections, medications, surgery and lifestyle. ${ }^{14}$ Our patient has not responded to previous treatments from conservative to interventional. 1) The specifics of his physical therapy (PT) program are crucial; did he undergo an active program which progressed to a home exercise program or just passive treatments alone? If the latter, reinitiating a wellprescribed and carried out PT program is an option. Evaluation by a pain psychologist is necessary for his chronic pain treatment program. Other options are osteopathic manipulation ${ }^{15}$ and acupuncture. 2) Indications for spinal injections will not be discussed but injections were unsuccessful. Other therapeutic injection treatments are limited. 3) Pharmacologically, he did not respond to one NSAID and cyclobenzaprine, resulting in treatment with opioids, and he is currently on high dose long-acting oxycodone. NSAID treatment options were not exhausted, as there is inter-individual variation among patients in their response to a specific drug. Therefore, if chronic LBP does not respond to one NSAID, there is a reasonable likelihood that the patient may respond to another NSAID. ${ }^{16}$ Additionally, other medications such as tramadol should be trialed prior to oxycodone for non-neuropathic axial LBP. 4) There is no indication for surgery. 5) Lifestyle changes include weight loss. ${ }^{17}$ These proposed multimodal treatments should be included in a comprehensive pain program as an ideal treatment.

The American Pain Society and American Academy of Pain Medicine published guidelines in 2009 which stated, "chronic opioid therapy can be effective therapy for carefully selected and monitored patients with chronic non cancer pain." 18 This statement makes several lofty assumptions that doctors can adequately select and monitor patients. Tools besides traditional history, physical and experience must be implemented and monitored. The PCP has neither selected nor regulated this patient's opioid treatment.

The approach to a patient in this situation is difficult because he is taking high dose longacting opioids and is dependent. Preferably the referring physician should have consulted a physiatrist earlier in this case so that management would be a dynamic process with treatments trialed with strategies stated above before initiation or titration of opioids. With him on long-acting oxycodone without methods of screening or monitoring puts the consultant in a precarious situation. If the consultant is willing to take over management then an agreement regarding titration downward with a signed drug agreement with clear expectations of monitoring or referral for detoxification and/or buprenorphine $\mathrm{HCl} /$ naloxone HCIdihydrate program is necessary. This patient has become part of the epidemic and requires help.

\section{Work}

In regard to work, the self-reported minimal discomfort allowing him to work on the current medication is both reassuring and concerning. He wants to continue working and is not placing undue financial stress on the public or placing himself at risk for the complications of long-term disability. But, he poses a risk to himself and others by driving while being under the influence of high dose opioids. This concern will need to be explored. 


\section{Conclusion:}

The benefit versus harm profile of his current regiment is unacceptable but is the path of least resistance to a busy clinician, especially with the enticing self-reported ability to continue working. The responsible treatment plan to the patient, society, and the healthcare system is to intervene towards non-opioid treatment for the patient and help end the epidemic. This will take more than one healthcare provider. Significant time and patient commitment is required but evidence shows that the patient will be healthier with less risk of future complications and less long-term financial stress on the health care system if he is treated without the use of long-term opioid medications. The second opioid epidemic is present without end in sight. However, by meticulously intervening with a multidisciplinary treatment program, we can help prevent this patient from being the next victim. 


\section{REFERENCES}

${ }^{1}$ McCoy A. The Politics of Heroin in Southeast Asia. Harper 1973.

${ }^{2}$ Portenoy, RK, Foley KM. Chronic use of opioid analgesics in non-malignant pain: Report of 38 cases. Pain 1986;25:171-186.

${ }^{3}$ Lee TJ. Pharmacologic Treatment for Low Back Pain: One component of pain care. Phys Med Rehabil Clin N Am 2010;21:793-800.

${ }^{4}$ Martin BI, Deyo RA, Mirza SK et al. Expenditures and health status among adults with back and neck problems. JAMA 2008;299:656-64.

${ }^{5}$ Kuehn BM. Opioid prescriptions soar: increase in legitimate use as well as abuse. JAMA 2007;297:249-51.

${ }^{6}$ Arnow BA et al. Comorbid depression, chronic pain, and disability in primary care. ec 2006;68:262-268.

${ }^{7}$ Compton WM, Volkow ND. Major increases in opioid analgesic abuse in the US: concerns and strategies. Drug Alcohol Depend 2006;81:103-7.

${ }^{8}$ Eriksen J, Sjogren P, Bruera E et al. Critical issues on opioids in chronic non-cancer pain: an epidemiological study. Pain 2006;125:172-9.

${ }^{9}$ Maretell BA, et al. Systemic review: opioid treatment for chronic back pain: prevalence, efficacy, and association with addiction. Ann Intern Med 2007;146:116-27.

${ }^{10}$ Dunn K, Saunders K, Rutter C, et al. Opioid prescriptions for chronic pain and overdose: a cohort study. Ann Intern Med 2010;152:85-92.

${ }^{11}$ Martin B, Deyo R, Mirza S, et al. Expenditures and health status among adults with back and neck problems. JAMA 2008;299:656-64. 
${ }^{12}$ Gatchel R, Okifuji A. Evidence-based scientific data documenting the treatment and cost-effectiveness of comprehensive pain programs for chronic nonmalignant pain. $J$ Pain 2006;7:779-93.

${ }^{13}$ Gallagher R. Biopsychological pain medicine and mind-brain-body-science. Phys Med Rehabil Clin N Am 2004;15:855-82.

${ }^{14}$ Personal correspondence with Freedman MK. 12/28/2011.

${ }^{15}$ Andersson GB; Lucente T; Davis AM et al. A Comparison of Osteopathic Spinal Manipulation with Standard Care for Patients with Low Back Pain N Engl J Med 1999; 341:1426-1431.

${ }^{16}$ Ashburn MA, Lipman AG, Carr D, et al. Principles of Analgesics Use in the Treatment of Acute Pain and Cancer Pain. 5th ed. Glenview, IL: American Pain Society, 2003.

${ }^{17}$ Leboeuf-Yde C, Kyvik KO, Bruun NH. Low back pain and lifestyle. Part II. Obesity. Information from a population-based sample of 29,424 twin subjects. Spine 1999;24:77984.

${ }^{18}$ Chou R, Fanciullo GJ, Fine PG et al. Clinician guidelines for the use of chronic opiod therapy in chronic non caner pain. J Pain 2009;10:113-30. 